\title{
ALBA VALDEZ NA IMPRENSA BRASILEIRA
}

\author{
MELO, Carlos Augusto de ${ }^{1}$ \\ SANTOS, Jéssica Aparecida Souza ${ }^{2}$ \\ SOUZA, Keyle Sâmara Ferreira de ${ }^{3}$
}

\begin{abstract}
RESUMO: Este artigo tem o intuito de relembrar o nome de Alba Valdez, escritora e educadora cearense, cujas obras estiveram engajadas em lutas pelos direitos da mulher. Ela produziu diversos textos em periódicos, revistas e almanaques, os quais necessitam ser reencontrados e reapresentados pela historiografia literária. Para tanto, as reflexões sobre essas contribuições de Alba Valdez para literatura brasileira basearam-se na metodologia de repertório bibliográfico, levando em consideração subsídios teóricos e críticos de pesquisadores como Norma Telles (2018), Constância Lima Duarte (2001), Maria do Sameiro Fangueiro (2020), de Cecília Prada (2010), dentre outras autoras, as quais ressignificam a história das mulheres e de sua escrita no contexto de resistência feminina por meio da literatura.
\end{abstract}

PALAVRAS-CHAVE: Escritoras, Alba Valdez, Periódicos

\section{ALBA VALDEZ IN THE BRAZILIAN PRESS}

\begin{abstract}
This article intends to remember the name of Alba Valdez, writer and educator from Ceará, whose works were engaged in struggles for women's rights. She produced several texts in periodicals, magazines and almanacks, which need to be found and re-presented by literary historiography. Therefore, the reflections on these contributions by Alba Valdez to Brazilian literature were based on the bibliographic repertoire methodology, based on theoretical and critical subsidies from works by Norma Telles (2018), Constância Lima Duarte (2001), Maria do Sameiro Fangueiro (2020),
\end{abstract}

\footnotetext{
${ }^{1}$ Professor de Literatura do Instituto de Letras e Linguística (ILEEL) e do Programa de Pós-graduação em Estudos Literários (PPLET) na Universidade Federal de Uberlândia (UFU). E-mail: carlosaug.melo@ufu.br

${ }^{2}$ Doutoranda em Estudos Literários do Programa de Pós-Graduação em Estudos Literários da Universidade Federal de Uberlândia - UFU. E-mail: jessica.santos1 @ufu.br

${ }^{3}$ Professora da Rede Estadual do Ceará. Mestra em Letras pela UESPI, Doutora em Letras pela UFPB. E-mail: keyle.souza@prof.ce.gov.br.
}

Jangada | nr. 16, jun/dez, 2020 | ISSN 2317-4722 
Cecília Prada (2010), which give new meaning to the history of women and their writing in the context of female resistance through literature.

KEYWORDS: Women writers, Alba Valdez, Nineteenth Century Press

A mulher é um ser fraco, propalam. Pois, da própria fraqueza, construirei a força necessária para comunicar as minhas emoções. (VALDEZ, 1937)

\section{PALAVRAS PRELIMINARES}

Falar da escrita de mulheres na formação literária brasileira é adentrar um caminho complexo de violências, misoginias e exclusões, mas também de lutas, empoderamentos e fortalecimentos identitários. Lembrar-se de nomes de escritoras brasileiras que ajudaram na formação literária nacional se configura uma prática necessária, uma vez que vai de encontro aos massacres do esquecimento pelos quais as mulheres ficaram submetidas por conta de modelos socioculturais de silenciamento e de seu enclausuramento, bem como de uma recepção crítica literária constituída pelos vieses majoritariamente masculinos e antifeministas.

Nas últimas décadas, graças ao fortalecimento de pesquisas sobre a História das Mulheres, sob os impulsos das orientações teórico-sociológicas dos Estudos Culturais e de Gênero, oriundas de instituições nacionais e internacionais, como, por exemplo, os estudos de Zahidé Lupinacci Muzart, tem sido possível questionar as lacunas na história da literatura, cujos valores foram constituídos por uma ordem discursiva de padrões culturais que marginalizavam os sujeitos femininos, tornando-a menos centralizada e bem mais democrática, eliminando os espaços de subalternidade aos quais muitas escritoras foram subjugadas. Aos poucos, confirmase que na memória cultural brasileira, muitas mulheres estiveram na linha de frente e desafiaram seu tempo para que, em liberdade, pudessem garantir seus lugares no mundo, os quais sempre lhes foram de direito.

Embora houvesse, no entresséculos XIX e XX, uma ordem machista contrária, de sempre querer colocar as mulheres em situações de inferioridade, de submissão, de incapacidade e de limitação intelectual, sabe-se que, aos poucos, elas contrariaram essa lógica, resistiram a ela e se afirmaram mulher, de acordo com as possibilidades de seu tempo. O discurso hegemônico 
masculino quis abafar os protagonismos femininos, e contar versões tangenciadas sobre o assunto, como um velado dispositivo de insegurança de perder o lugar do poder, da dominação e da exploração. No máximo, segundo Henrique Samyn, os homens vislumbraram um feminismo que, "desprovido de qualquer agenda emancipatória", completamente estanco de seus valores políticos, conservasse "uma profusão de elementos considerados tipicamente femininos desde uma perspectiva conservadora" (SAMYN, 2019, p. 46). Para vencerem as estratégicas de submissão e de dominação masculina, as mulheres de nosso passado literário conseguiram (re)existir por meio da palavra escrita, da literatura propriamente dita, registrada principalmente na memória dos periódicos.

É nesse caminho que este artigo quer estar, na contracorrente das práticas preconceituosas de nossa história, à medida que busca tirar as nódoas que, até então, encobriram os nomes das mulheres que, sem dúvida alguma, contribuíram para a formação cultural brasileira. Propõe-se questionar uma parte da história da literatura brasileira que quis impor olhares preconceituosos sobre escritoras, cujos trabalhos trouxeram leituras do mundo, da vida, do social, das subjetividades, de maneiras significativas que permitem infinidades de experiências identitárias aos mais heterogêneos leitores contemporâneos. Aqui, o foco será na produção das mulheres oitocentistas, em especial, a da cearense Alba Valdez, pseudônimo de Maria Rodrigues Peixe, que foi uma das pioneiras das letras brasileiras, bem como do movimento emancipatório pelos direitos femininos no país.

\section{AS CONTRIBUIÇÕES POLÍTICAS, SOCIAIS E LITERÁRIAS DAS MULHERES OITOCENTISTAS}

No Brasil, o século XIX representa um expressivo período de transformações para as mulheres, brancas e burguesas, a partir das lutas dos movimentos sociais e feministas, das quais foram protagonistas. Tiveram de lutar com determinação contra uma educação familiar, totalmente castradora e limitante, cujos valores impostos eram direcionados ao fortalecimento do ideal feminino que, submetido às vontades masculinas, encontrava-se como papéis sociais únicos de esposa e mãe, donas de casa e responsáveis unicamente pela instrução dos filhos, bem-estar e lazer do marido, “um ser de virtudes, ou anjo do lar.” (TELLES, 2018, p. 403)

Pensar sobre a situação que viviam as mulheres no Brasil do início do século XIX é saber que grande parte vivia em isolamento em suas próprias casas, sob a "proteção" familiar, sem acesso à educação ou à cultura, como apresenta Duarte (2004). Portanto, às brasileiras se fazia Jangada | nr. 16, jun/dez, 2020 | ISSN 2317-4722 
necessário a aquisição do direito básico da escrita e da leitura, como também o acesso ao estudo de nível superior de forma igualitária. Distinta daquela que as instruía para se tornarem "boas" esposas e mães, sendo educadas em conventos ou com professoras particulares, para as famílias de classe elevada. A instrução escolar foi uma das bandeiras de luta da Liga Feminista Cearense, associação fundada no Ceará, em 1904, por Alba Valdez e um grupo de mulheres que discutia literatura, escrevia e queria alfabetizar suas patrícias.

Segundo Duarte (2004), a primeira legislação relacionada à educação feminina é do ano de 1827, assim, mesmo que o acesso à educação tenha, a partir desse momento, caminhado a passos lentos, pois não a situação não atingira a todas as mulheres, a situação começou a se modificar. Portanto para

aquelas primeiras (e poucas) mulheres que tiveram uma educação diferenciada, que tomaram para si a tarefa de estender as benesses do conhecimento às demais companheiras, e abriram escolas, publicaram livros, enfrentaram a opinião corrente que dizia que a mulher não necessitava saber ler nem escrever. (DUARTE, 2004, p. 198)

Ao ter acesso à educação, a mulher letrada passa a propagar às outras, que estavam alheias ao processo de dominação, a possibilidade que tinham de sair dessa condição de subalternidade e alienação. Muitas delas, então, passaram a entender a situação na qual estavam imersas e a reagir contra a educação moralista daquele período, preocupando-se em espalhar e multiplicar os conhecimentos adquiridos, cientes de que deveriam levá-los àquelas que viviam em situações semelhantes.

De fato, as mulheres oitocentistas precisaram desconstruir o que, como instrumento de moralização, no gênero romanesco, propriamente arquitetado sob o ponto de vista machista, construía como padrão social e cultural de mulher. As tentativas de escapar a essas regras patriarcais, buscando ultrapassar os limites sufocantes dos muros dos lares, foram fortalecidas por mulheres que, tendo acesso a uma formação filosófica e letrada diferenciada, experimentaram o ofício de serem escritoras, visto como verdadeiro exercício de resistência feminina às construções sociais da época, tendo como influências e confluências os ideais de mulheres europeias, como Jane Austen, as irmãs Brontë, George Elliot.

Para que a mulher saísse dessa condição, ela teve que se enxergar de forma inversa ao que lhe fora imposto, causando muitas dificuldades e demora para que seus trabalhos e direitos 




fossem alcançados. A mulher precisava, além de transformar a forma como era vista socialmente, desconstruir o espaço ficcional que as transformavam em personagens de pouco valor, frágeis, vazias e/ou vulgares:

As concepções estéticas predominantes no século XIX que afirmavam ser a criação cultural um dom exclusivamente masculino, durante muito tempo confundiram as escritoras, artistas e as leitoras. Escrever, ler e pensar não só eram estranhos ao seu universo como podiam ser inimigos das características femininas (TELLES, 2012, p.61).

No período, a maioria dos críticos literários brasileiros, oriundos de uma formação machista e conservadora, não reconhecia que as mulheres possuíam competência intelectual para o domínio de uma escrita mais elaborada. Mantê-las à margem da instrução era a manutenção do controle, marcas de certa "colonização masculina", uma vez que se forjou a ideia de que a educação letrada não seria de nenhuma forma apropriada ao perfil brasileiro de mulher. Por muito tempo o ato de criação artística, de fabulação, de pensamento e de expressão foi negado às mulheres, resignadas a compartilharem da ideia de que não lhes cabiam tais ações, inapropriadas a uma "dama" de família. Em uma de suas publicações na imprensa, na Revista da Academia Cearense de Letras (1940), Alba Valdez relata suas memórias de infância e adolescência, ilustrando dessa forma a educação que era ofertada às mulheres em casa, na escola primária do século XIX, bem como, em seu segundo e último livro Dias de Luz (1907), por meio de um relato de suas memórias como normalista, já havia narrado e, de certo modo, questionado a educação secundária das mulheres nas Escolas Normais.

Nesse contexto, é importante destacar que as obras literárias escritas por mulheres recebiam o rótulo pejorativo de "coisas de mulher", categoria misógina que rebaixava toda a produção intelectual feminina a um lugar de inferioridade se comparado à do homem. Sob o fardo de uma ordem patriarcal, restavam às escritoras oitocentistas julgamentos críticos que, a partir do processo de generificação da literatura, rotulavam-nas de produtoras de estilos literários relacionadas diretamente às qualidades físicas e morais femininas, idealizadas pelos homens, que permitiam torná-las submissas ao poder masculino.

Para esses representantes da ordem patriarcalista brasileira, os textos literários das mulheres apresentavam características como a sensibilidade, a delicadeza, a graciosidade, a sentimentalidade, a emoção, a virtuosidade, o pudor, a beleza, entre outros. Essas características 
eram valorizadas apenas em um plano idealizado, íntimo, no qual as mulheres frequentavam como fruto de plena objetificação e/ou idealização, ou seja, ficavam circunscritas à ordem da vida privada, da inspiração e da convenção dos homens; se, todavia, transpostas a circunstâncias das quais elas poderiam ser sujeitos, como a função de escritora, reduziam-nas a valores pejorativos, inválidos e de inferioridade que, portanto, poderiam empobrecer a literatura nacional.

Naquela época, como se sabe, a mulher era vista geralmente como um sujeito inferiorizado, incapaz intelectualmente, características que não poderiam frequentar o universo masculino ao qual a Literatura pertencia forjadamente. Sendo assim, no "século XIX, para as mulheres que pensaram ser algo mais do que "bonecas" ou personagens literárias, os textos dos escritores colocaram problemas tanto literários quanto filosóficos, metafísicos e psicológicos" (TELLES, 2018, p. 408).

Foram diversos os constrangimentos pelos quais tiveram de passar as escritoras brasileiras no Oitocentos para garantirem certa credibilidade literária, estreito espaço nas instâncias de legitimação cultural brasileira, conforme acorreu à poeta Francisca Júlia, aconselhada por Severiano Rezende para que procurasse "ocupações mais úteis; dedi[casse] aos trabalhos de agulha" (FLEIUSS, 1941, p. 46), quando este rejeitara os seus versos. Não por acaso, a escritora passou por outras situações similares antes de se afirmar poeta, a exemplo da acusação de plágio ou, a mais conhecida delas, a equivocada recepção de João Ribeiro ao negar a autoria feminina aos primeiros poemas de Mármores, que a poeta havia submetido à revista A Semana, como nos lembra o crítico Max Fleiuss: "João Ribeiro exclamou logo - isto não é escrito de mulher! Araripe e Lúcio riram-se e confirmaram a suspeita de João Ribeiro" (FLEIUSS, 1941, p. 45).

A escritora Alba Valdez também vivenciou situações análogas às de Francisca Júlia, como se registra na crítica ao seu primeiro livro Em Sonho...fantasias (1901), publicada na Revista da Academia Cearense de Letras (1902), em uma resenha de Rodrigues Carvalho sobre as obras literárias mais recentes dela. A crítica é dura e não disfarça a misoginia ao conceituar o livro como "agradável", estereótipo que caracterizava a escrita feminina à época, sugerindo que a autora devesse usar seu talento para a produção de um livro de contos infantis, para realçar a sua opinião de que o livro era cheio de devaneios, um conjunto monótono e sem sentido.

Nesse contexto, percebe-se que a crítica literária do final do século XIX e início do XX resumia os trabalhos literários das mulheres "a um falso pudor e a monótona lamúria (...)" (BILAC, 1895, p. 1). E, quando se deparavam com a potência da escrita dessas mulheres, esses Jangada | nr. 16, jun/dez, 2020 | ISSN 2317-4722 
literatos utilizavam-se do argumento de que elas copiavam os estilos másculos, viris, que só eram possíveis de serem praticados por homens. O crítico João Ribeiro era contrário a essa apropriação do masculino, afirmando, na década de 1890, que "o estilo de literatas era um estilo pouco delas, cheirando a estilo masculino, sem nota pessoal, sem a mais tênue expressão da feminilidade, de ternura, de encanto." (REZENDE, 1891, p. 1). Nos jornais e revistas oitocentistas, eram corriqueiros comentários que atacavam as escritoras brasileiras. Na crônica "De domingo a domingo", publicada pelo Correio Paulistano, sob a assinatura de um possível pseudônimo, chamado Saulo, de quem ainda não descobrimos a autoria, o articulista defendia com convicção que:

A ciência de ser mãe é tão complexa que absorve toda a atividade, toda a inteligência da boa mulher, que torna a casa um santuário e um baluarte.

Se à mulher moderna está reservada essa missão sublime, porque se há de acoroçoar aquela, que, sem proveito algum para as letras e em desvantagem para a família, alinha meia dúzia de versos e vem para público sujeitá-los à crítica. (SAULO, 1890, p. 1)

Os atos coercitivos dos homens oitocentistas, representantes do universo das letras brasileiras, buscavam silenciar as poucas escritoras por meio de rótulos de "mediocridade ou inferioridade intelectual", "versos lamuriantes", "penas débeis", "estilo pouco delas", reproduzindo um pensamento misógino sobre as mulheres de uma sociedade que as obrigava “à esfera doméstica e às funções definidas como 'as únicas dignas' do sexo feminino (casamento e maternidade)", afastando-as "do mundo do saber e mantidas ignorantes, analfabetas ou apenas educadas com vernizes sociais, sabendo um pouco de francês, bordado, etiqueta. E muita religião é claro.” (PRADA, 2010, p. 30)

Essas considerações resumem o ideário masculino em contraponto às manifestações intelectuais de resistências das mulheres oitocentistas, consideradas pioneiras nesse exercício de passarem de objetos a sujeitos de sua história, como foram as pioneiras Nísia Floresta, Maria Firmina dos Reis, Ana Amélia, Francisca Júlia da Silva, Júlia Lopes de Almeida, Josefina Álvares de Azevedo, Alba Valdez, entre outras. Neste artigo, interessa-nos esta última, que tanto contribuiu, política e literariamente, para a história da literatura e cultura brasileiras.

A imprensa foi o berço da escrita das mulheres, possível veículo de construção de uma identidade feminina emancipatória. Os jornais, revistas e almanaques não foram meros suportes Jangada | nr. 16, jun/dez, 2020 | ISSN 2317-4722 
textuais, uma vez que eles influenciaram e caracterizaram a escrita de autoras e autores em seu momento. E isso pode ser averiguado nos gêneros literários escritos por Alba Valdez, como a crônica, contos, poesias, cujas relações estreitas entre a literatura e os periódicos acabam por se retroalimentarem e se transformarem.

\section{O PAPEL DE ALBA VALDEZ NA IMPRENSA}

A epígrafe "A mulher é um ser fraco, propalam. Pois, da própria fraqueza, construirei a força necessária para comunicar as minhas emoções" (VALDEZ, 1937), que abre este artigo, retirada do discurso de Alba Valdez, proferido na sessão do Quinquagenário do Instituto do Ceará, revela a força e potencial argumentativos de que a sua autora se armou para conseguir batalhar pelos direitos de fala - e, de certo modo, de existência - das mulheres brasileiras, nascidas no século XIX. A escritora e educadora Maria Rodrigues Peixe, mulher de destaque no meio letrado que usou o pseudônimo Alba Valdez, publicou diversas obras literárias, colaborou para jornais, revistas e almanaques, tanto do Ceará como de outros estados brasileiros. Nascida em 12 de dezembro de 1874, na vila de São Francisco de Uruburetama, atualmente conhecida como Itapagé, no Estado do Ceará. Mudou-se para a cidade de Fortaleza em 1877, juntamente com os pais, João Rodrigues Peixe e Isabel Alves Rodrigues Peixe, para fugir da seca que assolava sua terra natal.

Estabelecida em sua nova cidade, Almeida reitera que Alba Valdez "fez seus primeiros estudos na capital cearense, na escola primária de Isabel Teófilo Spinosa. Em março de 1886 matriculou-se na Escola Normal do Ceará, na qual foi aluna de Francisca Clotilde" (ALMEIDA, 2012, p. 114), que foi uma das que se engajou pela educação e formação intelectual das mulheres de sua época. Desde muito jovem deu mostras promissoras do futuro que teria, pois antes "mesmo de completar os dezesseis anos, em 1889, diplomou-se com brilhantismo, razão por que foi imediatamente nomeada para uma cadeira do ensino público, onde permaneceu até se aposentar" (DUARTE, 2004, p. 626). Nesse mesmo ano, Alba Valdez publicou uma de suas primeiras produções em jornais, o poema "Os Sonhos", no jornal de Fortaleza chamado Constituição (1889), na edição de sábado em 02 de fevereiro.

Após atingir o grau de professora, Alba Valdez lecionou no interior, Aracatiaçu e Baturité, até conseguir uma vaga na capital e voltar a morar em Fortaleza, onde trabalhou no Grupo Escolar Nogueira Accioly, que tinha como diretora Ana Facó, nome também importante na luta pelo direito à educação e à literatura de autoria feminina brasileira no século XIX. 
Sua trajetória foi marcada por seu engajamento em questões políticas, sociais e culturais, e, assim empenhou-se na luta "pela emancipação feminina e pelo direito ao voto, numa época em que o preconceito gerava muitas barreiras aos direitos da mulher" (FANGUEIRO, 2020, p. 1). Outro aspecto que demonstra o envolvimento de Alba Valdez pela causa feminina é a fundação da Liga Feminista Cearense, em 1904, juntamente com Maria Portugal, Aurelinda Simões, Olga Alencar, Amélia Alencar e Júlia Moura, mulheres que estavam empenhadas com o desenvolvimento cultural da sociedade cearense, assim como o reconhecimento dos direitos da mulher, pontua Fangueiro (2020).

Deste grupo destacamos as irmãs Olga e Amélia Alencar que fundaram o jornal $O$ Astro, que começou a ser publicado em Baturité e, depois, em Fortaleza. Sousa (1937), em ensaio biográfico sobre os membros do Instituo Histórico do Ceará, afirma que Alba Valdez foi uma das fundadoras d'O Astro. Porém, não há evidências que comprovem isso, a não ser o tempo que Alba Valdez viveu em Baturité.

O afinco da escritora Alba Valdez no cenário literário cearense e o convite de Justiniano de Serpa fez com que em 1922 ingressasse na Academia Cearense de Letras, assumindo a cadeira 8 (oito), que tinha Álvaro Martins como patrono, tornando-se a primeira mulher a ingressar nessa academia. Integrou-se ao Instituto Ceará e à Academia Feminina de Letras, ocupando a Cadeira 16 que tinha como patrona Francisca Clotilde, como pontua Duarte (2004) e Almeida (2012). Participou ainda do "Centro Literário, da Iracema Literária, da Bohemia Literária e da Sociedade Cearense de Geografia e História, além da Ala Feminina da Casa de Juvenal Galeno" (VASCONCELOS, 2018, p. 20).

Foi um nome constante no meio jornalístico, com uma extensa publicação em periódicos de seu tempo, tais como Revista da Academia Cearense de Letras; Revista do Ceará (1905); Panóplia (1914); Diário do Ceará entre 1917-1919; Correio do Ceará entre 1921-1922; A Tribuna (1922); A Razão (1919); Unitário (1955); O Nordeste (1927); Jornal do Commercio (1930); Diário do Recife (1935); Iris de Porto Alegre (1920). Várias produções de Alba Valdez foram encontradas em arquivos públicos do Ceará e da Hemeroteca Digital da Biblioteca Nacional por meio da pesquisa de Doutorado de Souza (2019) que, em sua Tese "Alba Valdez: a palavra das mulheres na história da Literatura e da Imprensa cearense", elaborou levantamento, iconografia de periódicos e transcrições de textos, inclusive de manuscritos inéditos da autora.

A obra de Valdez compõe-se também da publicação de Em Sonho, em 1901, "que consistia em uma coletânea de textos em prosa, semelhantes a contos e crônica" (DUARTE, Jangada | nr. 16, jun/dez, 2020 | ISSN 2317-4722 
2004), sendo que alguns desses textos foram traduzidos para o sueco e para o francês. Posteriormente, em 1907 publica a obra Dias de Luz, "um romance memorialista de cento e vinte páginas, no qual registra suas lembranças" (ALMEIDA, 2012, p. 115) da adolescência na Escola Normal. As memórias de infância estão no texto "Nosso lar, nossa escola" (1940). Outro texto publicado em um jornal parisiense, Le Matin, foi o conto A Carta.

Em seu artigo sobre Alba Valdez, Duarte (2004) fez uma relação dos textos da referida autora, que até aquele momento era de conhecimento público. Seguem os títulos abaixo:

Em Sonho. Fortaleza: [s.n], 1901 (contos e fantasia);

Dias de Luz. Fortaleza: [s.n], 1906. (Romance memorialista);

Textos Exparsos

"Eterna história" (conto) Revista Ceará, Fortaleza, 1905.

“Uma definição de Gross". Panóplia, Fortaleza, n. 4, 1914.

"Discurso" por ocasião da feta inaugural de três escolas noturnas sob os auspícios da Liga Cearense contra o Analfabetismo, pronunciado no palacete da Fénix Caixeira, Diário do Ceará, Fortaleza, 1917;

“Às Senhoras Cearenses”, Correio do Ceará, 1919.

“Ceará, terra do Brasil”, Íris, Porto Alegre, 1920.

"A sempre nova questão do ensino". Ano Escolar. NOGUEIRA, Joaquim da Costa (org.) Prefácio de Clóvis Bevilacqua. Fortaleza: [s.n.], 1921. (Livro de leitura adotado pelas escolas públicas primárias do Ceará.)

"Discurso" em homenagem à memória de Dom Pedro II e de D. Teresa Cristina, por ocasião do repatriamento dos despojos dos ex-imperadores. Correio do Ceará, Fortaleza, 1921.

“O espírito popular cearense”. (Ensaio.) Almanach do Ceará, Fortaleza, 1922.

“O nacionalismo". Correio do Ceará, Fortaleza, 1922.

"Carta a Rodolfo Teófilo". A Tribuna, Fortaleza, 1922.

“O horrível morbus". O Nordeste, Fortaleza, 1927.

"O horrível brasileiro". (Ensaio.) A Razão, Fortaleza, 1929.

"De pé, Jornal do comércio, 1930". (Artigo sobre a exclusão das mulheres da Academia Brasileira de Letras).

"Mensagem da mulher cearense à mulher pernambucana", Diário da Manhã, Recife, 1935. 
"Uma grande figura da história educacional do Ceará". (Esboço de uma biografia do prof. José de Barcelos). Separata da Revista do Instituto do Ceará (1948). Fortaleza, Instituto do Ceará, 1949.

"A bela missão de Ana Facó". Unitário, Fortaleza, 1955. (Palestra pronunciada no Instituto do Ceará por ocasião do centenário de nascimento da ilustre romancista e teatróloga cearense) (DUARTE, 2004, p. 630-631).

Essa lista foi significativamente ampliada se se considerarem os trabalhos de Odalice Castro e Silva (2019) e Keyle Sâmara Ferreira de Souza (2019). O primeiro trouxe livro, como parte de uma coletânea sobre as mulheres brasileiras e portuguesas, publicada pelo Almanaque de Lembranças Luso-Brasileiras. O segundo foi, conforme comentado anteriormente, uma pesquisa de Doutorado, realizada na UFPB, campus João Pessoa, com o propósito de rastrear e ampliar a biobibliografia de Alba Valdez, identificando produções de 1889 até janeiro de 1962, aproximadamente um mês antes da morte da autora. Souza (2019), através do cotejamento de periódicos, acrescentou: "Os sonhos" (Poema), Constituição, Fortaleza, 1889; "Noturno" (Crônica), Diário de Notícias, Gram-Pará-Belém, 1897; "Folha de um livro" (Ensaio), A Tribuna, Natal 1901; "Folha solta (página cearense)", A capital, Niterói-RJ, 1903. Na Revista O Lírio, de Recife, um periódico de mulheres, Alba Valdez publicou "A Boda" (1903), “Descrição Cearense” (1903), "Visão do Crepúsculo" (1903), “O Beija-flor” (1904), "Coração" (1904). Este último, no mesmo ano, também foi publicado em A Cidade, de Sobral/CE, jornal no qual Alba Valdez publicou "A utilidade do jornal” (1904). O levantamento da obra de Alba Valdez realizado pela pesquisadora Keyle de Souza reuniu 72 produções da escritora, inclusive dois textos inéditos manuscritos "Palavras ao luar" e "Fantasias do Verão". Ambos os textos ainda não foram publicados, sendo localizados no arquivo do sobrinho de Alba Valdez, Mozar Monteiro, escritor, que hoje se encontra na Casa Juvenal Galeno, localizada em Fortaleza (SOUZA, 2019).

Além dos títulos acima, destacamos aqui o do ano de 1937, publicado pela Revista do Instituto do Ceará em decorrência do cinquentenário do instituto. O período de circulação desse texto corresponde também ao que Alba Valdez exercia a função de bibliotecária da diretoria do referido instituto e era membro da comissão de Ciências e Letras. Esse discurso, publicado posteriormente no periódico do Instituto do Ceará, destaca-se pelo resumo da história das mulheres que lutaram e de outras que escreveram e publicaram na imprensa e literatura do Ceará. Em sua escrita é possível perceber o seu engajamento nas lutas sociais, regionais ou em 
âmbito nacional, seja relacionada à educação feminina e pública ou política. Sobre a sua posição feminista, Vasconcelos (2018) afirma que Alba Valdez foi:

Feminista declarada, lutou pelos direitos das mulheres, defendendo o voto feminino e a igualdade entre os sexos. Criou a primeira agremiação literária feminina do Estado em 1904, a Liga Feminista Cearense, contando com nomes como Francisca Clotilde e reunindo mulheres antes excluídas do cenário das letras. Foi a primeira mulher a ingressar na Academia Cearense de Letras, ocupando a cadeira de número 22. (VASCONCELOS, 2018, p. 76)

A cearense Alba Valdez sempre presente na luta feminista, organizando formas de luta e exercendo sua participação ativa, reunindo-se com outras mulheres escritoras, buscando com a organização da Liga unir forças para a conquista de seus direitos, uma vez que a "causa feminista sempre foi para ela motor. Tinha consciência do papel das mulheres, na época em que vivia, mas não queria que fosse assim. Queria poder fazer e ser mais. E queria também incentivar outras mulheres a fazerem e serem mais" (VASCONCELOS, 2018, p. 82). Em uma entrevista concedida ao Jornal $O$ Estado em 24 de junho de 1945, Alba Valdez afirmou que, "Não deve ser negado à mulher o direito de votar e de ser votada. E neste ponto a atual legislação satisfaz a medida das aspirações femininas" (VALDEZ, 1945 apud VASCONCELOS, 2018, p. 82). Sua fala reforçava a sua luta pela emancipação feminina das imposições masculinas e pela conquista do voto que seria apenas um passo nesse largo caminho de muitas reivindicações. Uma das conquistas alcançadas pelas mulheres foi o direito ao voto em 1932, ato que foi muito defendido e comemorado pela referida escritora.

Retomando ao texto escrito por Alba Valdez, mencionado anteriormente, que foi publicado na Revista Instituto do Ceará, a escritora abordou a seca sofrida pelo Estado do Ceará a tudo o que fazia morrer a intelectualidade à época, assim interrogava: “Qual há sido, em regra geral, o destino dos nossos grêmios culturais? Vegetações que morreram na primeira fase do crescimento. Algumas nem chegaram a ter tamanhinho, pereceram no embrião" (VALDEZ, 1937, p. 423). Nessa analogia com a seca, ainda no discurso de 1937, em homenagem ao Cinquentenário do Instituto do Ceará, Alba Valdez comparou os escritores, que segundo ela, saíram do Ceará para se desenvolverem mais intelectualmente, longe das agruras dos longos 
períodos de estiagens, com as mulheres, que aqui permaneceram e mesmo diante das intempéries climáticas cearenses, escreveram e publicaram.

Outro ponto que aqui destacamos deste texto de Alba Valdez é sua abordagem em relação ao papel desempenhado pela mulher, no meio social e literário. Teceu esse tema da seguinte forma: "Que fazer? Tudo em mim é fraqueza. A mulher é um ser fraco, propalam. Pois, da própria fraqueza, construirei a força necessária para comunicar as minhas emoções" (VALDEZ, 1937, p. 424). Usou da própria visão sobre a mulher que até então estava presente no contexto brasileiro para se manifestar, qual seja, um ser frágil construído pela tradição, mas que se expressava e tinha como "arma" a sua escrita.

Por conseguinte, Alba Valdez escreveu sobre a educação feminina, cujas escolas eram divididas pela condição financeira das famílias cearenses: as meninas ricas estudavam no colégio interno da Imaculada Conceição e às meninas pobres eram destinadas a Escola Normal. Fez ainda referência às leituras destinadas às mulheres, sendo "que reservavam aos romances de Escrich e George Ohnet e às poesias de Casemiro de Abreu, Castro Alves, e Olavo Bilac, que surgira com a sua musa cálida, - poesias que decoravam e recitavam ao som da Dalila" (VALDEZ, 1937, p. 425). Apresentou tais obras e escritores para elucidar o tipo de leitura que se recomendava às mulheres, grande parte pertencente ao romance, cujos enredos foram utilizados como forma instrução para a mulher, criando personagens servissem de modelo para a conduta de suas leitoras. Usado como um auxiliador na educação feminina, segundo a tradição patriarcal.

$\mathrm{Na}$ continuação deste texto, em sua fala sobre a mulher e a luta feminina, Alba Valdez citou os nomes de Bárbara Pereira da Alencar, Ana de Alencar Araripe (conhecida como Ana Triste), Jovita Feitosa, Maria Tomásia Figueira Lima, Francisca Clotilde, Antonieta Clotilde, D. Maria Felismina e Ana Facó, mulheres que contribuíram de forma significativa com o embate feminino pela educação, direitos e voz. Mulheres que não somente atuaram em escolas, mas também no meio político, literário e jornalístico.

Ainda sobre este texto, o qual destacamos alguns trechos, Duarte afirma que nos proporciona "conhecer sua opinião lúcida, e algo irônica, sobre a importância da participação das mulheres na política e no desenvolvimento dos países" (DUARTE, 2004). Dessa forma, apesar de não haver muitos estudos sobre a sua obra, é possível perceber que foi uma escritora preocupada com a posição da mulher do entre séculos XIX e XX, vinda de tradição patriarcal limitadora, que só começou a se modificar no século XX com o fortalecimento dos movimentos 
feministas, os quais se empenharam na luta pela efetivação dos direitos políticos e sociais das mulheres, como também por sua instrução e lugar social.

Alba Valdez foi uma escritora possuidora de uma escrita cuidadosa e detalhista, transmitindo por meio da descrição do espaço as minúcias e os pormenores da ambientação narrativa. Para ainda exemplificar a escrita de Alba Valdez, a seguir apresentamos alguns trechos da primeira parte do conto intitulado "Coração", publicado no periódico A cidade (CE) em 16 de junho de 1904, que em sua escrita usou-se de um tom bucólico ao descrever a paisagem: "Raio despontava inundado de fulgores e aromas. O campo ria de verde e nos quintais plantados o vermelho variegado das rosas, o branco latescente dos cravos, o púrpuro das boninas atraíam o olhar numa orgia deslumbrante de cores" (VALDEZ, p. 1, 1904). Transgredindo seu tempo pelo domínio da escrita literária, Alba Valdez deixava claro que, assim como os escritores, podia utilizar-se dos padrões de estilos narrativos do período, apresentando suas personagens masculinas e femininas de uma maneira descritiva tradicional, ressaltando, principalmente, as qualidades físicas delas, como se pode perceber neste trecho do conto:

A Julia Menezes! Aquela era que se podia chamar mulher bonita, com uns olhos que pareciam mais estrelas, pele alva, corada e estatura tirando para alta. $\mathrm{O}$ vestido de luto, justo no corpo, emprestava-lhe uns toques de melancolia poética e interessante. A fala cheia e harmoniosa vibrava semelhante a uma caricia.

Jorge tinha a fama de guapo rapaz e bom partido e quando se referiam ao par achavam-no muito igual (VALDEZ, p.1, 1904).

Percebe-se que a escritora cearense oferece destaque à personagem feminina em comparação à masculina. Ela buscava deixar as mulheres mais em evidências nas narrativas e nos poemas, representando os diversos papéis sociais, Observando esse aspecto em relação à personagem feminina, expomos ainda o poema "Mãe e Filha" escrito por Alba Valdez:

Mãe e Filha

Quando contemplo minha mãe querida.

Olhos sem brilho, lacrimosos, baços,

Alva a cabeça, pelas cãs, perdida,

Tez enrugada, descarnados braços

À pequenita, em maternais abraços 
A rir, beijando-a carinhosa e fida,

Murmuro: __ A estrela que guiou-me os passos

Se abraça ao sol que me ilumina a vida!

Uma é a tarde a desmaiar tristonha,

Outra a alvorada que surgiu risonha,

Lá no horizonte de dourada cor. (VALDEZ, p. 221, s/a)

No poema vê-se que os versos iniciais que se direcionam a descrever as qualidades da figura materna, como se prestasse uma espécie de homenagem à maternidade. A mãe é aquela que, mesmo cansada e com o peso dos anos, consegue sempre estar presente, abraçando, acalentando, cuidando e iluminando a vida da filha. A mãe é alguém iluminada, de grandeza comparada a elementos naturais que, como o Sol, são constantes e insubstituíveis, geradores de vidas, ou seja, é uma mulher essencial na sociedade.

\section{CONCLUSÃO}

Atualmente, após vários séculos de silenciamento, pensar nos enfrentamentos das mulheres escritoras em periódicos, espaço intelectual e literário ainda dominado pela política do gênero masculino, é imperativo falar sobre a escrita feminina, cujo resgate pode trazer à tona a história de mulheres que, como a de Alba Valdez, escreveram, publicaram, frequentaram os espaços masculinos, construíram seus próprios lugares de escrita e de fala, demonstraram aos diversos públicos como serem exemplos de luta em movimentos sociais pelos seus direitos políticos, sociais, culturais e literários.

Após esta exposição sobre Alba Valdez, percebe-se que por meio de seus vários textos publicados em periódicos, revistas e almanaques, ela contribui para a imprensa e a história literária brasileira. Foi uma mulher engajada e reconhecida no meio literário cearense, frequentando ciclos importantes para literatura, ingressando na Academia de Letras Cearense e participando do Instituto de Ciências, como membro da diretoria. Teve representatividade na educação, uma vez que, desde o término de seus estudos secundários, ingressou na docência e permaneceu até se aposentar. A representatividade social da autora de Em sonho pode ser reconhecida através do cotejamento de jornais de sua época, os quais registram as suas participações em relevantes eventos intelectuais, como palestrante na Fenix Caixeiral, associação dos comerciantes de Fortaleza. 
Como foi visto, a participação dela não parou por aí, pois fortaleceu ativamente o movimento feminista e a luta dos direitos das mulheres, ao lado de outras escritoras, como Nísia Floresta, Maria Benedita Bormann, Inês Sabino que, segundo Muzart, "mostrou alta consciência de suas possibilidades literárias e da importância de preservar os nomes das outras escritoras, analisando-lhes o desempenho, num arremedo de crítica literária, em Mulheres ilustres do Brazil." (MUZART, 2004, p. 26).

Ao apontar para os dois exemplos deixados aqui, os trechos do conto "Coração" e o poema "Mãe e Filha", confirma-se o que disse Odalice de Castro a respeito da escrita de Alba Valdez: "quando começou a escrever seus livros não deu nenhuma importância a convenções de gêneros, literários ou não. Escrita de si para si do outro. Para educar na liberdade e pessoas, Alba Valdez cruzou os limites de seu tempo" (SILVA, 2019, p. 20). A escrita da escritora cearense tem a capacidade de nos surpreender por sua singularidade, a sua forma de pensar e demonstrar seu empenho nos movimentos de luta feminista. Assim, torna-se primordial a retomada de seus escritos, tanto para pesquisas como para leva-los ao público leitor.

Portanto, podemos concluir que Alba Valdez é um nome importante na história da literatura brasileira, e, não foi uma escritora que escrevia entre as paredes de sua casa e lá permanecia. Foi uma escritora potente que conhecia e participava do cenário literário e da imprensa do Ceará e de outros estados brasileiros. Possuidora de uma vasta obra, principalmente em se tratando de textos publicados em periódicos, o que se faz necessário colocá-la como uma das grandes escritoras representantes da cultura e literatura brasileiras.

\section{REFERÊNCIAS BIBLIOGRÁFICAS}

ALMEIDA, Gildênia Moura De Araújo. Mulheres Beletristas e Educadoras: Francisca Clotilde na Sociedade Cearense - de 1862 a 1935. Tese (doutorado) - Universidade Federal do Ceará, Faculdade de Educação, Programa de Pós-Graduação em Educação Brasileira, Fortaleza, 2012. BILAC, Olavo. Crônica. A Cigarra: hebdomadário. Rio de Janeiro, ano I, n. 10, p. 2-3, quintafeira, 11 jul. 1895 .

DUARTE, Constância Lima. Alba Valdez. In: MUZART, Zahidé. (Org.) Escritoras brasileiras do século XIX: antologia. Florianópolis: Editora Mulheres, v. 2, 2004, p.626-637.

Feminismo e literatura: discurso e história. In: $O$ eixo e a roda. Belo Horizonte,

UFMG, v 9/10, 2003/2004. p. 195219. Disponível em: http://www.letras.ufmg.br/poslit. Acesso em: 20 de Julho de 2020. 
FANGUEIRO, Maria do Sameiro. Alba Valdez. Biblioteca Nacional Digital: Periódicos e Literatura. Disponível em: https://bndigital.bn.gov.br/dossies/periodicosliteratura/personagens-periodicos-literatura/alba-valdez/. Acesso em: 20 de Julho de 2020. FLEIUSS, Max. Recordando... (casos e perfis) - separata do Instituto Histórico e Geográfico Brasileiro. Rio de Janeiro: Imprensa Nacional, 1941.

MUZART, Zahidé. (Org.) Escritoras brasileiras do século XIX: antologia. Florianópolis: Editora Mulheres, v. 2, 2004.

PRADA, Cecília. A pena e o espartilho. $2^{\text {a }}$ ed. São Leopoldo: Editora Unisinos, 2010.

REZENDE, Severiano. Mulher-homem. O Mercantil, São Paulo, ano VII, n. 1940, p. 1, sextafeira, 27 fev. 1891.

SAMYN, Henrique Marques. Da "poetisa bonita" à "máscula autora": sobre a generificação de Francisca Júlia. In: Miscelânea, Assis, v. 25, p. 39-60, jan.-jun. 2019.

SILVA, Odalice Castro e. Alba Valdez: 1874-1962. Lisboa: BNP, CLEPUL, CICS - NOVA, 2019.

SOUSA, Eusébio de. Maria Rodrigues (Alba Valdez). In: . Meio século de existência: subsídio para a história do Instituto do Ceará, 1987-1937. Fortaleza: Tipografia Minerva, 1937.

SOUZA, Keyle Sâmara Ferreira de. Alba Valdez: a palavra das mulheres na história da Literatura e da Imprensa Cearense. Tese. João Pessoa: UFPB, 2019.

TELLES, Norma. Escritoras, escritas, escrituras. In: DEL PRIORE, Mary (org.). História das mulheres no Brasil. 10ª ed. São Paulo: Contexto, 2018.

Encantações: escritoras e imaginação literária no Brasil, Século XIX. São Paulo: Intermeios, 2012.

TEREZINHA SCHMIDT, Rita. Centro e margens: notas sobre a historiografia literária. Estudos de Literatura Brasileira Contemporânea, Brasília: Universidade de Brasília, n. 32, p. 127-141, 2008. Disponível em: https://www.redalyc.org/articulo.oa?id=323127096010. Acesso em: 20 de Julho de 2020.

VALDEZ, Alba. Seção 2: Discurso em comemoração ao Quinquagenário do Instituto do Ceará. Revista do Instituto do Ceará, Fortaleza, 04 mai. 1937, p. 422-430. Disponível em: http://memoria.bn.br/DocReader/DocReader.aspx?bib=166774\&Pesq=Alba\%20Valdez\&pagf is $=415$. Acesso em: 20 de Julho de 2020. . Coração. A Cidade (CE) - 1899 a 1904. Acesso em: 22 de Janeiro de 2021. 
. Mãe e Filha. In: MUZART, Zahidé. (Org.) Escritoras brasileiras do século XIX: antologia. Florianópolis: Editora Mulheres, v. 2, 2004.

VASCONCELOS, Anna Heloisa de. Ipomeias: mulheres do século XIX na imprensa cearense. Monografia. Universidade Federal do Ceará, Instituto de Cultura e Arte - ICA, Curso de Comunicação Social - Jornalismo, Fortaleza, 2018. 